\title{
Extratos de Aroeira, Angico, Umburana e Quebra-faca no controle de Lasiodiplodia theobromae em cachos da videira cv. Itália
}

\author{
Georgia de Souza Peixinhoํㅡㄹ Caio Márcio Guimarães Santos², Valtemir Gonçalves Ribeiro³, Edna Peixoto da Rocha \\ Amorim $^{4}$, Valdeir Nunes Carvalho ${ }^{4}$, Jaciara de Souza Bispo ${ }^{1}$
}

\begin{abstract}
${ }^{1}$ Mestranda do Programa de Pós-graduação em Horticultura Irrigada, pela Universidade do Estado da Bahia (UNEB), Juazeiro- BA, CEP 48905680. ${ }^{2}$ Instituto Federal Pernambucano (IF-SERTÃO), Petrolina- PE, Zona Rural CEP 56314-520. ${ }^{3}$ UNEB- Departamento de Tecnologia e Ciências Sociais, Juazeiro-BA, CEP 48905-680, ${ }^{4}$ Universidade Federal de Alagoas, Centro de Ciências Agrárias, Rio Largo-AL, CEP 57082000.

Autor para correspondência: Georgia Souza Peixinho (geopeixinho@gmail.com)
\end{abstract}

Data de chegada: 19/02/2016. Aceito para publicação em: 24/02/2017.

$10.1590 / 0100-5405 / 2155$

\section{RESUMO}

Peixinho, G.S.; Santos, C.M.G.; Ribeiro, V.G.; Amorim, E.P.R.; Carvalho, V.N.; Bispo, J.S.. Extratos de Aroeira, Angico, Umburana e Quebra-faca no controle de Lasiodiplodia theobromae em cachos da videira cv. Itália. Summa Phytopathologica, v.43, n.2, p.158-160, 2017.

O objetivo deste estudo foi avaliar o efeito dos extratos vegetais sobre L. theobromae pela utilização de produtos como método alternativo. Foi analisado o crescimento micelial de L. theobromae em placas de Petri contendo o meio BDA suplementado com os extratos de Aroeira, Angico, Umburana e Quebra-faca nas concentrações de 10, 20 e 30\%. Para avaliação do efeito direto dos extratos sobre o desenvolvimento de $L$. theobromae, cachos da cv Itália foram inoculados com o patógeno e, após $4 \mathrm{~h}$, pulverizados com os diferentes extratos: Angico e Umburana (30\%) e
Quebra-faca (10\%). Água destilada esterilizada (ADE) foi utilizada como testemunha. Posteriormente, para avaliar o potencial dos extratos como indutores de resistência, cachos da cv Itália foram submetidas aos mesmos tratamentos e, inoculados após 4 horas com L. theobromae. Os resultados mostraram que os extratos de Angico e Umburana nas concentrações de $30 \%$, inibiram o crescimento micelial in vitro em 61,66 e $60 \%$ respectivamente, contudo os extratos testados não foram eficientes em inibir a incidência e a severidade da doença.

Palavras-chave: produtos alternativos, doenças fúngicas, fitossanidade

\section{ABSTRACT}

Peixinho, G.S.; Santos, C.M.G.; Ribeiro, V.G.; Amorim, E.P.R.; Carvalho, V.N.; Bispo, J.S.. Extracts of Brazilian peppertree, angico, amburana and "quebra-faca" on Lasiodiplodia theobromae control in bunches of grape cv. Itália. Summa Phytopathologica, v.43, n.2, p.158-160, 2017.

The aim of this study was to evaluate the effect of plant extracts on $L$. theobromae by using products as an alternative method. Mycelial growth of $L$. theobromae was analyzed on Petri dishes containing PDA medium supplemented with extracts of Brazilian peppertree, angico, amburana and "quebra-faca" at the concentrations of 10, 20 and $30 \%$. To evaluate the direct effect of extracts on the development of L. theobromae, bunches of grape cv Itália were inoculated with the pathogen and, after $4 \mathrm{~h}$, sprayed with the different extracts: angico and amburana (30\%) and "quebra-faca" (10\%). Sterile distilled water (ADE) was used as control. Subsequently, to evaluate the potential of extracts as resistance inducers, bunches of grape cv Itália were subjected to the same treatments and inoculated, after 4 hours, with $L$. theobromae. Results showed that extracts of angico and amburana at the concentration of $30 \%$ inhibited in vitro mycelial growth by 61.66 and $60 \%$, respectively; however, the tested extracts were not efficient in inhibiting the disease incidence and severity.

Keywords: alternative products, fungal diseases, plant health

A viticultura brasileira com área cultivada de aproximadamente 83.700 hectares, variando a produção anual entre 1.300 e 1.400 mil toneladas vem se destacando como uma importante atividade agrícola. No ano de 2010, a comercialização com uvas para mesa foi de aproximadamente $57 \%$, sendo o restante da produção destinada à produção de vinhos e suco de uva (7).

As doenças de pós-colheita têm grande impacto nas perdas, chegando a $50 \%$, antes de chegar ao consumidor, e o produto que chega, nem sempre apresenta a qualidade desejada (10).

Antes considerado um fungo oportunista, Lasiodiplodia theobromae (Patouillard) Griffon \& Maublanc (sinônimo: Botryodiplodia theobromae Pat.) (9), vem se apresentando como um sério problema para diversas frutíferas.

Produtos naturais vêm sendo utilizados no controle de doenças de plantas, apresentando eficiência, contribuindo para a redução do uso de defensivos agrícolas (5).
Desta forma, visando encontrar alternativas ao controle, realizouse este trabalho com o objetivo de obter o controle de Lasiodiplodia theobromae com o uso de extratos de Aroeira, Angico, Umburana e Quebra-faca.

Os experimentos foram conduzidos no laboratório de Pós-colehita do Instituto Federal do Sertão Pernambucano (IF - Sertão), Campus Petrolina Zona Rural e no laboratório de Fitopatologia, no Centro de Ciências Agrárias (CECA), da Universidade Federal de Alagoas (UFAL), em Rio Largo.

No laboratório de Pós-colheita (IF- Sertão), os extratos foram preparados utilizando folhas frescas de cada espécie, triturando $5 \mathrm{~g}$ de material vegetal em $50 \mathrm{~mL}$ de ADE por cerca de 5 minutos em processador e filtrados em gaze dupla, após a preparação foram adicionados ao meio de cultura BDA, fundente $\left(45-50^{\circ} \mathrm{C}\right)$ e vertidos em placas de Petri de $9 \mathrm{~cm}$ de diâmetro, sendo usadas 5 placas para cada combinação/concentração de extrato/fungo: 10, 20 e $30 \%$ 
para os extratos de Aroeira (Schinus molli L.), Quebra-faca (Croton conduplicatus), Angico (Anadenthera macrocarpa (Benth.) Brenan) e Umburana (Amburana cearensis), e água (testemunha). Todos os extratos foram esterilizados em luz UV por 30 minutos antes de serem adicionados ao meio autoclavado (1).

No centro de cada placa foi depositado um disco de meio BDA, de 0,6 cm de diâmetro, contendo crescimento micelial fúngico, sendo retirado das bordas da colônia do patógeno cultivado em meio de cultura BDA, após oito dias, mantido em condições ambientais de $28^{\circ} \mathrm{C}$ e foto período de 12 horas. Após cinco dias da inoculação, à temperatura de $28^{\circ} \mathrm{C}$ e fotoperíodo de 12 horas, foi determinado o diâmetro médio da colônia tomado no reverso das placas de Petri, através da medição em dois sentidos diametralmente opostos, e por comparação com o crescimento das colônias nas placas testemunhas, que receberam o meio de cultura sem os tratamentos, foi calculado a percentagem de inibição do crescimento micelial (P.I.C.), (4).

No Laboratório de Fitopatologia (UFAL) foi avaliado o efeito direto dos extratos sobre o desenvolvimento de L. theobromae, em cachos da videira cv. Itália. Os cachos foram inoculados com o patógeno, onde as bagas sofreram ferimentos utilizando lâmina esterilizada e pulverizada com uma suspensão de conídios na concentração de $10^{5}$ direcionado para cada cacho, e, após $4 \mathrm{~h}$, aspergidos com diferentes concentrações dos extratos: Quebra-faca 10\%, Umburana e Angico $30 \%$ e água (testemunha).

Posteriormente, com o objetivo de avaliar o potencial dos extratos na tratamento preventivo, os cachos foram aspergidos com solução de extratos vegetais: Aroeira 10\%, Umburana, Angico 30\% e água (testemunha). Após $4 \mathrm{~h}$ inoculados (Ensaio 2).

Nos ensaios os cachos foram dispostos sobre papel absorvente para retenção do excesso de umidade e secagem sob ventilação e permaneceram a $25 \pm 1{ }^{\circ} \mathrm{C} / 85-95 \%$ UR até o momento da inoculação. Os cachos inoculados foram acondicionados em sacos plásticos e mantidos a $25 \pm 1{ }^{\circ} \mathrm{C} / 80-90 \%$ UR, por 48 horas, em câmara úmida, e avaliada após um período de seis dias, quanto à incidência e severidade (escala de notas adaptada para Lasiodiplodia theobromae (3)). Os cachos foram pulverizados com $10 \mathrm{~mL}$ de cada extrato.

A escala de notas adotada para avaliação da severidade da doença variou de 1 a 6 , com base na área da lesão, correspondendo, aproximadamente, a 2, 5, 10, 20,30 e 50\% da área da baga lesionada, respectivamente. Os resultados foram expressos em índice de doença calculado através da fórmula: ID $(\%)=\{[(\mathrm{n} 1 * 1)+\ldots+(\mathrm{n} 6 * 6)] *(6 * \mathrm{~N})-1\}$ $* 100$, onde, $\mathrm{n} 1 \ldots 6=\mathrm{n}^{\circ}$ de bagas infectadas com a respectiva nota e $\mathrm{N}$ $=\mathrm{n}^{\circ}$ total de bagas inoculadas. $\mathrm{O}$ delineamento experimental utilizado foi o inteiramente casualizado, com 13 tratamentos e cinco repetições (ensaio 1), e quatro tratamentos e cinco repetições (ensaio 2). Os valores obtidos foram submetidos a análise de variância, teste $\mathrm{F}$, e quando os efeitos de tratamentos apresentarem diferença significativa $(P<0,01)$ as médias foram comparadas por meio do teste de regressão.

De acordo com os dados apresentados na Figura 1, os extratos de Angico e Umburana nas concentrações de 30\%, inibiram o crescimento micelial in vitro em 61,66 e $60 \%$ respectivamente, diferindo significativamente em relação à testemunha. Os extratos de Aroeira e Quebra - faca não apresentaram diferença entre as concentrações testadas.

A capacidade de inibição de crescimento micelial de fungos pela ação de extratos vegetais foi observado por diversos pesquisadores. Lima et al. (6) ao avaliar o efeito de vários extratos vegetais sobre o crescimento de $L$. theobromae, verificaram que o extrato etanólico de
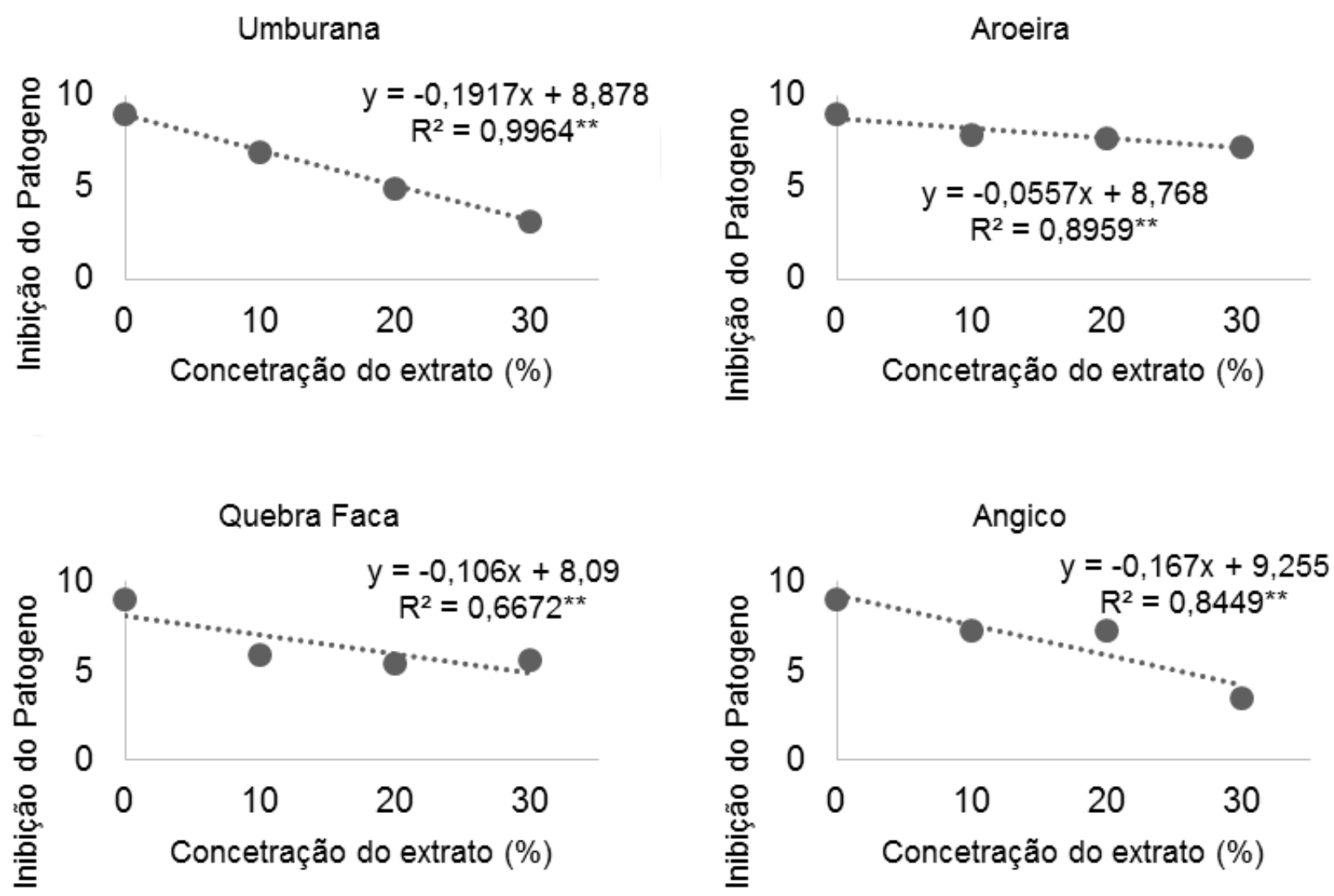

Figura 1. Efeito dos indutores de resistência sobre o crescimento micelial de L. theobromae 
Tabela 1. Efeito de produtos naturais nos tratamentos curativo e preventivo sobre o controle de L. theobromae

\begin{tabular}{ccccc}
\hline & Incidência Prev. & Severidade Prev. & Incidência Curat. & Severidade Curat. \\
Quebra faca 10\% & $8.2 \mathrm{a}$ & $5.1 \mathrm{a}$ & $9.6 \mathrm{a}$ & $5.5 \mathrm{a}$ \\
Angico 30\% & $8.8 \mathrm{a}$ & $6.0 \mathrm{a}$ & $10.0 \mathrm{a}$ & $6.0 \mathrm{a}$ \\
Umburana 30\% & $10.0 \mathrm{a}$ & $5.2 \mathrm{a}$ & $10.0 \mathrm{a}$ & $6.0 \mathrm{a}$ \\
Testemunha & $10.0 \mathrm{a}$ & $6.0 \mathrm{a}$ & $9.2 \mathrm{a}$ & $6.0 \mathrm{a}$ \\
\hline
\end{tabular}

Médias seguidas por mesma letra, não diferem entre si, pelo teste de Tukey a 5\% de probabilidade.

Alecrim apresentou $100 \%$ de inibição do crescimento desse fungo, enquanto os extratos de Jurema-Preta, Aroeira, Catingueira, Maniçoba e Angico apresentaram 46,45\%; 30,34\%; $21,89 \% ; 15 \%$; e 9,12\% de inibição, respectivamente, discordando dos dados apresentados neste trabalho, com relação à ação da Aroeira (19,25\%) e Angico (61,66\%).

Os resultados relativos aos efeitos dos extratos, no tratamento curativo (Ensaio 1), e preventivo (Ensaio 2) mediante a determinação da incidência e severidade da podridão seca (L. theobromae) podem ser observados na Tabela 1. Com relação à incidência e severidade, pôde-se observar que nenhum tratamento diferiu estatisticamente da testemunha.

Oliveira et al. (8) avaliando a severidade da podridão-negra (Chalara paradoxa) em abacaxizeiro 'Pérola', verificaram que no sexto, sétimo e oitavo dias após a inoculação, os frutos tratados com extratos de Melão-de-são-Caetano e Angico apresentaram resultados promissores no controle da doença.

Bomfin et al. (2), verificando o efeito de alguns extratos vegetais, incluindo extratos de Aroeira e Umburana, constataram que estes não apresentaram capacidade de proteger o sistema radicular do tomateiro contra o parasitismo do nematoide $M$. mayaguensis.

Para o controle na pós- colheita, os extratos não apresentaram eficiência na inibição do desenvolvimento do fungo. Entretanto testes com extratos, com outras formulações e na pré- colheita são necessárias para verificar a eficiência dos produtos no controle da doença.

\section{REFERÊNCIAS}

1. Barguil, B.M.;. Oliveira, S. M. A.; Coelho, R. S. B. Ocorrência de Colletotrichum gloeosporioides em Heliconia chartacea cv. Sex Pink. Fitopatologia Brasileira, Brasília, v.30, p.S136. 2005.

2. Bomfim, B.S.A.; Rodrigues, C.S.; Coimbra, J.L; Lopes C.M.L. Efeito de extratos vegetais obtidos de plantas do Cerrado baiano no desenvolvimento de Meloidogyne mayaguensis. Revista de Biologia e Ciências da Terra, São Cristóvão, v. 11, n. 1, 2011.

3. Camili, E. C.; Benato, E. A.; Pascholati, S. F.; Cia, P. Avaliação de quitosana, aplicada em pós-colheita, na proteção de uva 'Itália' contra Botrytis cinerea. Summa Phytopathologica, Botucatu, v.33, p.3, p.215-221, 2007.

4. Edgington, L.V.; Khew, K.L.; Barron, G.L..Fungitoxic spectrum of benzimidazole compounds. Phytopathology, Reino Unido, v.61, p.42-44. 1971.

5. Kimati, H., et al. Manual de fitopatologia: doenças de plantas cultivadas. São Paulo: Editora Agronômica Ceres Ltda, 1997. v.2, 587f

6. Lima JS; Perez JO; Barros PN; Azevedo LC; Mendes RB; Pessoa RA. Ação fungitóxica de extratos vegetais de plantas da caatinga sobre o crescimento micelial deLasiodiplodia theobromae (Pat.) Griffon \& Maubl.em Vitis vinifera L. In: Congresso Norte-Nordeste de Pesquisa e Inovação 5., 2010. Anais... Maceió: CONNEPI. p. 23-26, 2010.

7. Mello, L. M. R. Vitiviniculura brasileira: Panorama 2010. Disponível em: $<$ http://www.cnpuv.embrapa.br/publica/artigos/prodvit2010.pdf $>$. Acesso em: 04 mai. 2014

8. Oliveira, M. D. M.; Nascimento, L. C. Avaliação da atividade de indutores de resistência abiótica, fungicida químico e extratos vegetais no controle da podridão-negra em abacaxi 'Pérola'. Revista Brasileira de Fruticultura, Jaboticabal, v. 31, n. 1, p. 84- 89, 2009.

9. Sutton, B. C. Coelomycetes: fungi imperfecti with pycnidia, acervuli and stromata. Kew: Surrey, England, C.M.I., 1980. p. 696.

10. Tavares, G.M.; Controle químico e hidrotérmico da antracnose em frutos de mamoeiro (CaricapapayaL.) na pós-colheita. 2004. 55f. Dissertação (Mestrado em Fitopatologia) - Departamento de Fitopatologia- Universidade Federal de Lavras, Lavras. 